\title{
Modificações dietéticas, reposição hídrica, suplementos alimentares e drogas: comprovação de ação ergogênica e potenciais riscos para a saúde
}

\author{
Dietary changes, water replacement, food supplements and drugs: \\ evidence of ergogenic action and potential health risks
}

\section{Editores: Arnaldo José Hernandez e Ricardo Munir Nahas}

Coeditores: Tânia Rodrigues, Flávia Meyer, Paulo Zogaib, José Kawazoe Lazzoli, João Ricardo Turra Magni, João Carlos Bouzas Marins, Tales de Carvalho, Félix Albuquerque Drummond, Samir Salim Daher

Participantes: Antonio Cláudio Lucas da Nóbrega, Carlos Alberto Werutski, Cláudio Baptista, Clayton Macedo, Cibele Crispin, Daniel Kopiler, Héldio Fortunato Gaspar de Freitas, Heloísa Vidigal Guarita Padilha, Jomar Souza, Marcos Aurélio de Oliveira Brazão, Marcos Girão, Marcelo Leitão, Marcelo Regazzine, Pablius Staduto Braga Silva, Paula Baptista, Serafim Borges, Suzana Bonumá

Realização: Sociedade Brasileira de Medicina do Exercício e do Esporte

Apoio: Gatorade Sports Science Institute (GSSI)

\section{Primeira Publicação \\ Editor: Tales de Carvalho}

Coeditores: Tânia Rodrigues, Flávia Meyer, Antonio Herbert Lancha Jr. e Eduardo Henrique De Rose

Participantes: Antonio Claudio Lucas da Nóbrega, Arthur Haddad Herdy, Carlos Alberto Werutski, Eney de Oliveira Fernandes, Félix Albuquerque Drummond, Glaycon Michels, lleana Kazapi, Kharla Medeiros, José Kawazoe Lazzolli, Luis Fernando Funchal, Luiz Aragon, Magnus Benetti, Marcelo Bichels Leitão, Marcelo Salazar, Marcos Aurélio de Oliveira Brazão, Michel Dacar, Rafael de Souza Trindade, Ricardo Munir Nahas e Turíbio Leite de Barros Neto

\section{INTRODUÇÃO}

A Sociedade Brasileira de Medicina do Exercício e do Esporte (SBME) mostrou preocupação com o crescente consumo de suplementos alimentares e drogas quando editou sua primeira publicação sobre o tema em 2003. Naquela ocasião, contou com colaboradores renomados em suas áreas de atuação que produziram um texto que passou a ser referência na elaboração de trabaIhos e matérias sobre o assunto. Este grupo de trabalho, acrescido de nomes não menos importantes, atualizou essas informações, conferiu dogmas e verificou novidades na área sempre tendo a saúde e o bem-estar daqueles que praticam atividade física regular como seu principal objetivo.

Nesta revisão, que mantém a estrutura da primeira publicação, constatamos que mudanças ocorreram, embora o consumo dessas substâncias ditas ergogênicas continue e seja crescente, muitas vezes são oferecidas como sendo a única resposta ao melhor rendimento nas diversas modalidades e práticas esportivas.

Devemos saudar o maior envolvimento das autoridades responsáveis pela regulamentação e fiscalização do comércio legal e ilegal destas substâncias em nosso país, ainda tímido, mas vindo ao encontro das necessidades e anseios daqueles que trabalham e pesquisam nas ciências dos esportes.

Infelizmente, pudemos também testemunhar o aparecimento de novas drogas e métodos, lícitos e ilícitos, que interferem no rendimento e são utilizados principalmente por atletas de alto rendimento, não obstante seu consumo ocorra também em academias, clubes e escolas de esportes, nas mais variadas modalidades, além da crescente utilização de substâncias proibidas, no uso e fabricação, mesmo sem interferir diretamente no desempenho esportivo.

Arnaldo José Hernandez e Ricardo Munir Nahas

\section{MODIFICAÇÕES DIETÉTICAS}

Não restam dúvidas quanto às mudanças favoráveis da composição corporal e a influencia positiva sobre o desempenho esportivo de atletas após o manejo dietético, através do uso da suplementação alimentar para casos específicos.

A alimentação saudável e adequada à quantidade de trabalho deve ser entendida e compreendida pelos atletas de alto rendimento como sendo o ponto de partida para obter o desempenho máximo e as manipulações nutricionais caracterizam uma estratégia complementar.

As orientações que constam nesta seção destinam-se a atletas saudáveis, adultos e adolescentes em fase de maturação sexual final. Para os indivíduos que praticam exercícios físicos sem maiores preocupações com o desempenho, uma dieta balanceada, que atenda às recomendações dadas à população em geral, é suficiente para a manutenção da saúde e possibilitar bom desempenho físico.

\section{AVALIAÇÃO NUTRICIONAL}

Ponto de partida para se conhecerem os hábitos alimentares e detectar imperfeições, a avaliação nutricional tem na anamnese criteriosa a oportunidade de estabelecer vínculo entre o atleta e o profissional de saúde, que permitirá mudanças favoráveis com objetivo de otimizar seu desempenho esportivo, sem prejuízo à saúde, respeitando suas preferências e regras atuais, e permitindo que as transforme em rotina.

As necessidades nutricionais podem ser calculadas através de protocolos apropriados, sendo estimadas por meio de tabelas próprias. Aqui, devem ser levados em consideração a modalidade esportiva praticada, a fase de treinamento, o calendário de competições e os objetivos da equipe técnica em relação ao desempenho, dados referentes ao metabolismo basal, demanda energética 
de treino, necessidades de modificação da composição corporal e fatores clínicos presentes, como as condições de mastigação, digestão e absorção. As necessidades energéticas são calculadas por meio da soma da necessidade energética basal (protocolo de livre escolha), gasto energético médio em treino e consumo extra ou reduzido para controle de composição corporal.

Levando-se em consideração o consumo calórico total e o tempo entre digestão e aproveitamento metabólico, determina-se a quantidade necessária de macronutrientes, ou seja, carboidratos, proteínas e lipídios, essenciais na manutenção ou melhora do desempenho esportivo e saúde do corpo humano.

Em relação aos micronutrientes, ou seja, vitaminas, minerais e oligoelementos, permanece o conceito de que, quando presentes em dietas balanceadas e com diversidade de alimentos, são suficientes para a demanda requerida pelos praticantes de atividade física regular, ficando a suplementação para ocasiões especiais, como em praticantes de atividade física com anemia ferropriva, gestantes, por exemplo.

O ajuste das dietas, em termos de macronutrientes, às maiores necessidades calóricas decorrentes das atividades desportivas, deve proporcionar um concomitante ajuste no consumo dos micronutrientes. Recomenda-se que sejam consideradas as orientações nutricionais destinadas à população em geral, calculadas proporcionalmente à cada 1.000 quilocalorias ingeridas. Desse modo, o incremento na oferta de micronutrientes é proporcional ao aumento calórico da dieta, mantendo-se o equilíbrio ou balanço nutricional em níveis adequados.

\section{RECOMENDAÇÕES}

\section{a) Valor da taxa calórica total da alimentação}

O equilíbrio de energia pode ser definido como a resultante zero entre a ingestão de alimentos, bebidas e suplementos, e seu consumo, pelo metabolismo basal, efeito térmico do alimento e a atividade física voluntária. Ingestão insuficiente de macro e micronutrientes, resultando em balanço calórico negativo, pode ocasionar perda de massa muscular e maior incidência de lesão, disfunções hormonais, osteopenia/osteoporose e maior frequência de doenças infecciosas, ou seja, algumas das principais características da síndrome do overtraining, comprometendo o treinamento pela queda do desempenho e rendimento esportivo.

A necessidade calórica dietética é influenciada pela hereditariedade, sexo, idade, peso e composição corporal, condicionamento físico e fase de treinamento, levando em consideração sua frequência, intensidade e duração e modalidade. Para esses, o cálculo das necessidades calóricas nutricionais está entre 1,5 e 1,7 vezes a energia produzida, o que, em geral, corresponde a consumo entre 37 e $41 \mathrm{kcal} / \mathrm{kg}$ de peso/dia e, dependendo dos objetivos, pode apresentar variações mais amplas, entre 30 e 50kcal/kg/dia. Tabelas com gasto energético estimado por minuto de prática estão disponíveis em diversas publicações, sinalizando para atletas do sexo masculino, praticantes de modalidades de longa duração, consumos que vão de 3.000 a $5.000 \mathrm{kcal}$ por dia. As necessidades energéticas para adultos de ambos os sexos, saudáveis, leve a moderadamente ativos, é de 2.000 a $3.000 \mathrm{kcal}$ por dia.
Por outro lado, quando a necessidade de redução de massa gorda é um dos objetivos do acompanhamento nutricional, devem-se monitorar os resultados periodicamente, para que a perda não seja também de massa magra, efeito indesejável para rendimento esportivo e saúde do atleta. Além disso, distúrbios alimentares podem ser desencadeados, dependendo da pressão que o atleta sofre para perder peso, e devem ser imediatamente inibidos, especialmente nas mulheres por serem mais suscetíveis a essas variações.

O ritmo de perda de peso em programas de redução de massa corporal deve ser de 0,5 a $1 \mathrm{~kg}$ por semana, devidamente aconselhada e monitorada por um profissional capacitado, através da ingestão calórica reduzida com a escolha de alimentos de baixa densidade energética e pobre em gordura.

Em atletas, a redução de 10 a 20\% na ingestão calórica total promove alteração na composição corporal, com redução de massa corporal de gordura, não induzindo fome e fadiga, como ocorre com dietas de muito baixo valor calórico. A redução drástica da gordura dietética pode não garantir a redução de gordura corporal e ocasionar perdas musculares importantes por falta de nutrientes ativos na recuperação após o exercício físico, como as vitaminas lipossolúveis e proteínas.

\section{b) Carboidratos}

O exercício prolongado reduz acentuadamente os níveis de glicogênio muscular, obrigando a constante preocupação com sua correta reposição, fundamental para manter seu efeito ergogênico, necessário em todas as atividades esportivas, em todos os seus níveis, mas principalmente nos de alta intensidade e longa duração. No entanto, observa-se baixa adesão dos atletas, de diferentes modalidades, ao seu consumo na quantidade correta.

A escolha dos alimentos fontes de carboidrato, assim como a preparação da refeição que antecede o evento esportivo, deve respeitar as características gastrintestinais individuais dos atletas. A recomendação do fracionamento da dieta em três a cinco refeições diárias deve considerar o tempo de digestão necessária para a refeição pré-treino ou prova. O tamanho da refeição e sua composição em quantidades de proteínas e fibras podem exigir mais de três horas para o esvaziamento gástrico. Na impossibilidade de esperar por esse tempo para a digestão, pode se evitar o desconforto gástrico com refeições pobres em fibras e ricas em carboidratos. Sugere-se escolher uma preparação com consistência leve ou líquida, com adequação na quantidade de carboidratos. Assim, a refeição que antecede os treinos deve ser suficiente na quantidade de líquidos para manter hidratação, pobre em gorduras e fibras para facilitar o esvaziamento gástrico, rica em carboidratos para manter a glicemia e maximizar os estoques de glicogênio, moderada na quantidade de proteína e deve fazer parte do hábito alimentar do atleta.

A energia consumida durante os treinos e competições depende da intensidade e duração dos exercícios, sexo dos atletas e o estado nutricional inicial. Quanto maior a intensidade dos exercícios, maior será a participação dos carboidratos como fornecedores de energia. A contribuição da gordura pode ser im- 
portante para todo o tempo em que durar o exercício, tendendo a se tornar mais expressiva quando a atividade se prolonga e se mantém em intensidade francamente aeróbia. Contudo, a proporção de energia advinda da gordura tende a diminuir quando a intensidade de exercício aumenta, o que exige maior participação dos carboidratos. A proteína, com a maior duração do exercício, aumenta sua participação, o que contribui para a manutenção da glicose sanguínea, principalmente por meio da gliconeogênese hepática.

Estima-se que a ingestão de carboidratos correspondente a 60 a 70\% do aporte calórico diário atende à demanda de um treinamento esportivo. Para otimizar a recuperação muscular recomenda-se que o consumo de carboidratos esteja entre 5 e $8 \mathrm{~g} / \mathrm{kg}$ de peso/dia. Em atividades de longa duração e/ou treinos intensos há necessidade de até $10 \mathrm{~g} / \mathrm{kg}$ de peso/dia para a adequada recuperação do glicogênio muscular e/ou aumento da massa muscular:

A quantidade de glicogênio consumida depende, naturalmente, da duração do exercício. Para provas longas, os atletas devem consumir entre 7 e $8 \mathrm{~g} / \mathrm{kg}$ de peso ou 30 a $60 \mathrm{~g}$ de carboidrato, para cada hora de exercício, o que evita hipoglicemia, depleção de glicogênio e fadiga. Frequentemente, os carboidratos consumidos fazem parte da composição de bebidas especialmente desenvolvidas para atletas. Após o exercício exaustivo, recomenda-se a ingestão de carboidratos simples entre 0,7 e $1,5 \mathrm{~g} / \mathrm{kg}$ peso no período de quatro horas, o que é suficiente para a ressíntese plena de glicogênio muscular.

\section{c) Proteínas}

As necessidades proteicas de atletas têm recebido atenção especial dos investigadores nas últimas décadas por fazerem parte essencial no reparo de microlesões musculares decorrentes da prática esportiva. Essas necessidades aumentam com o tipo de exercício praticado, sua intensidade, duração e frequência e não há uma definição em relação a diferenças quanto ao sexo.

Os exercícios de força exigem maior consumo de proteínas quando comparadas com as demandas exigidas pelos trabalhos de resistência. Para aqueles que têm por objetivo aumento de massa muscular, sugere-se a ingestão de 1,6 a 1,7 gramas por quilo de peso, por dia. Para os esportes em que o predomínio é a resistência, as proteínas têm um papel auxiliar no fornecimento de energia para a atividade, calculando-se ser de 1,2 a 1,6g/kg de peso a necessidade de seu consumo diário.

Os atletas devem ser conscientizados de que o aumento do consumo proteico na dieta além dos níveis recomendados não leva aumento adicional da massa magra. Há um limite para o acúmulo de proteínas nos diversos tecidos.

\section{d) Lipídios}

Um adulto necessita diariamente cerca de $1 \mathrm{~g}$ de gordura por $\mathrm{kg} /$ peso corporal, o que equivale a 30\% do valor calórico total (VCT) da dieta. A parcela de ácidos graxos essenciais deve ser de 8 a 10g/dia. Para os atletas, tem prevalecido a mesma reco- mendação nutricional destinada à população em geral, ou seja, as mesmas proporções de ácidos graxos essenciais, que são: 10\% de saturados, 10\% de polinsaturados e 10\% de monoinsaturados.

Alguns estudos sugerem um efeito positivo de dietas relativamente altas em gorduras no desempenho atlético e têm proposto a suplementação de lipídios de cadeia média e longa, poucas horas antes ou durante o exercício, com a finalidade de poupar o glicogênio muscular. Diante da falta de evidências científicas consistentes, recomenda-se não usar esse tipo de suplementação.

Por outro lado, os praticantes devem seguir essas recomendações gerais e assegurar que a ingestão de lipídios não seja excessivamente baixa. Estudos sugerem que níveis abaixo de 15\% do VET já produzem efeitos negativos. Quando dietas com restrição de lipídios forem necessárias, as cotas em relação ao aporte calórico total devem conter menos do que 8\% para as gorduras saturadas, mais do que $8 \%$ para as monoinsaturadas e de 7 a $10 \%$ para as polinsaturadas.

\section{e) Vitaminas}

Para atletas em regime de treinamento intenso, tem sido sugerido, o que tem gerado controvérsia, o consumo de vitamina $C$ entre 500 e $1.500 \mathrm{mg} /$ dia (proporcionaria melhor resposta imunológica e antioxidante) e de vitamina E (aprimoraria a ação antioxidante). A documentação científica permite que os profissionais qualificados, nutricionistas e médicos, prescrevam de forma sistemática vitamina C e E para atletas, com a ressalva de que esta atitude se baseia em baixo grau de evidência científica.

\section{f) Minerais}

O zinco está envolvido no processo respiratório celular e sua deficiência em atletas pode gerar anorexia, perda de peso significativa, fadiga, queda no rendimento em provas de resistência e risco de osteoporose, razão pela qual tem sido sugerida sua suplementação alimentar. Entretanto, as evidências científicas não justificam o uso sistemático do zinco em suplementação nutricional e, sim, quando o acompanhamento determinar a necessidade.

Atletas do sexo feminino, em dietas de restrição calórica, podem sofrer deficiências no aporte de minerais. É o caso do cálcio, envolvido na formação e manutenção óssea. Recomenda-se que a dieta contenha a quantidade mínima de $1.000 \mathrm{mg} /$ dia de cálcio.

A baixa ingestão de ferro, que ocorre em cerca de 15\% da população mundial, causa fadiga e anemia, afetando o desempenho atlético e o sistema imunológico. Recomenda-se atenção especial ao consumo de alimentos com ferro de elevada biodisponibilidade, com oferta recomendada de $15 \mathrm{mg} /$ dia para a população feminina e $10 \mathrm{mg} /$ dia para a masculina. Para as gestantes, a recomendação diária (RDI) se eleva para 30mg. Tais necessidades podem ser contempladas pela manipulação dietética, não sendo necessária a suplementação.

\section{g) Antioxidantes}

Os estudos demonstram que os mecanismos regulatórios promovidos pela ingestão combinada ou isolada de vitaminas C, A, E, de cobre e zinco e da coenzima Q10 produzem efeitos antioxidantes. 
No entanto, sua suplementação está reservada para atletas de alto desempenho, em que a oferta desses nutrientes através da dieta balanceada, suficiente na maioria dos casos, mostrar-se insuficiente. Altas doses podem não apresentar os efeitos esperados e ainda trazer prejuízos a saúde.

\section{REPOSIÇÃO HÍDRICA}

Uma hidratação apropriada durante a atividade física de caráter recreativo ou competitivo pode garantir que o desempenho esperado seja atingido e que problemas de saúde sejam evitados. Os procedimentos para assegurá-la requerem conhecimento de fatores que influenciam quando e o quanto beber de água. As recomendações dependem do tipo de atividade e de fatores individuais, como condicionamento físico, idade, modalidade praticada, estresse ambiental, entre outros.

O estresse do exercício é acentuado pela desidratação, que aumenta a temperatura corporal, prejudica as respostas fisiológicas e o desempenho físico, com riscos para a saúde. Esses efeitos podem ocorrer mesmo que a desidratação seja leve ou moderada, com até $2 \%$ de perda do peso corporal, agravando-se à medida que ela se acentua. Com 1 a 2\% de desidratação inicia-se o aumento da temperatura corporal em até $0,4{ }^{\circ} \mathrm{C}$ para cada percentual subsequente de desidratação. Em torno de 3\%, há redução importante do desempenho; com 4 a $6 \%$ pode ocorrer fadiga térmica; a partir de $6 \%$ existe risco de choque térmico, coma e morte.

Como o suor é hipotônico em relação ao sangue, a desidratação provocada pelo exercício pode resultar em aumento da osmolaridade sanguínea. Tanto a hipovolemia como a hiperosmolaridade aumentam a temperatura interna e reduzem a dissipação de calor pela evaporação e convecção. A hiperosmolaridade plasmática pode aumentar a temperatura interna, afetando o hipotálamo e/ou glândulas sudoríparas e retardando o início da sudorese e da vasodilatação periférica durante o exercício.

A desidratação afeta o desempenho aeróbio, diminui o volume de ejeção ventricular pela redução no volume sanguíneo e aumenta a frequência cardíaca. São alterações acentuadas em climas quentes e úmidos, pois a maior vasodilatação cutânea transfere grande parte do fluxo sanguíneo para a periferia, em vez da musculatura esquelética, ocasionando importantes reduções da pressão arterial, do retorno venoso e do débito cardíaco. A reposição hídrica em volumes equivalentes aos das perdas de água pela sudorese pode prevenir declínio no volume de ejeção ventricular, sendo, também, benéfica para a termorregulação, pois aumenta o fluxo sanguíneo periférico, facilitando a transferência de calor interno para a periferia.

O reconhecimento dos sinais e sintomas da desidratação é fundamental. Quando leve a moderada, ela se manifesta com fadiga, perda de apetite e sede, pele vermelha, intolerância ao calor, tontura, oligúria e aumento da concentração urinária. Quando grave, ocorre dificuldade para engolir, perda de equilíbrio, a pele se apresenta seca e murcha, olhos afundados e visão fosca, disúria, pele dormente, delírio e espasmos musculares.

A seguir (tabela 1), um resumo das principais alterações da desidratação induzida pelo exercício, conforme resultados de diversos estudos.
Tabela 1. Alterações provocadas pela desidratação

\begin{tabular}{|c|c|}
\hline AUMENTO & REDUÇÀO \\
\hline $\begin{array}{l}\text { Frequência cardíaca submáxima } \\
\text { Concentração de lactato } \\
\text { e osmolaridade sanguínea } \\
\text { Índice de percepção de esforço } \\
\text { Náuseas e vômitos } \\
\text { Requerimento de glicogênio } \\
\text { muscular } \\
\text { Temperatura interna: hipertermia } \\
\text { Doenças do calor: cãibras, exaus- } \\
\text { tão ou choque térmico }\end{array}$ & $\begin{array}{l}\text { Volume plasmático } \\
\text { Volume sistólico, débito cardíaco e } \\
\text { VO2max } \\
\text { Fluxo sanguíneo para pele e músculos } \\
\text { ativos, fígado e outros órgãos } \\
\text { Taxa de sudorese } \\
\text { Tempo para atividade contínua, pro- } \\
\text { longada e intensa } \\
\text { Pressão arterial } \\
\text { Componentes cognitivos } \\
\text { Motivação }\end{array}$ \\
\hline
\end{tabular}

Foi demonstrado ainda que a ingestão de líquidos, independente da presença de carboidrato, melhora o desempenho para a primeira hora de exercício aeróbio em alta intensidade. Como a desidratação decorrente do exercício pode ocorrer não apenas devido à sudorese intensa, mas, também, devido à ingestão insuficiente e/ou deficiente absorção de líquidos, é importante reconhecer os elementos que influem na qualidade da hidratação.

\section{Água}

A água é uma boa opção de reidratação para o exercício por ser facilmente disponível, barata e ocasionar esvaziamento gástrico relativamente rápido. Entretanto, para as intermitentes, de mais de uma hora de duração, ou para as atividades de menor duração e de elevada intensidade como o futebol, basquetebol, tênis e handebol, poderá apresentar as desvantagens de não conter sódio e carboidratos e de ser insípida, favorecendo a desidratação voluntária e dificultando o processo de equilíbrio hidroeletrolítico. A desidratação voluntária é verificada quando se compara a hidratação com água com a hidratação com bebidas contendo sabor.

\section{Sódio}

As reservas de eletrólitos, como a concentração de sódio no sangue, por exemplo, são muito bem reguladas pelos rins através de respostas hormonais da aldosterona e vasopressina. Porém, em muitas situações de exercício intenso e prolongado e hábitos alimentares restritivos, justifica-se a adição de alguns eletrólitos às bebidas esportivas, principalmente o sódio, e também cloro e potássio, a qualquer tempo.

A perda de sódio através da sudorese justifica sua ingestão durante o exercício, em algumas situações. Sua concentração no suor varia individualmente, de acordo com fatores como a idade, grau de condicionamento e a aclimatização ao calor. A concentração média de sódio no suor de um adulto está em torno de $40 \mathrm{mEq} / \mathrm{L}$. Supondo que um indivíduo de $70 \mathrm{~kg}$ corra por três horas e perca dois litros de suor por hora, a perda total de sódio é de $240 \mathrm{mEq}$, ou seja, $10 \%$ do total existente no espaço extracelular. Essa perda seria irrelevante, não fosse o risco de hiponatremia, concentração de sódio plasmático menor que $130 \mathrm{mEq} \cdot \mathrm{I}^{-1}$, decorrente de reposição hídrica com líquidos isentos de sódio ou com pouco sódio, principalmente em eventos muito prolongados. A diminuição da osmolaridade plasmática produz um gradiente osmótico entre o sangue e o cérebro, causando apatia, náusea, vômito, consciência alterada e convulsões, que são algumas das manifestações neurológicas da hiponatremia. 
A inclusão de sódio nas bebidas reidratantes promove maior absorção de água e carboidratos pelo intestino durante e após o exercício. Isso se dá porque o transporte de glicose na mucosa do enterócito é acoplado com o transporte de sódio, resultando em maior absorção de água.

Em exercícios prolongados, que ultrapassam uma hora de duração, recomenda-se beber líquidos contendo de 0,5 a 0,7g.l. l $^{-1}$ (20 a $\left.30 \mathrm{mEq} \cdot\right|^{-1}$ ) de sódio, que corresponde a concentração similar ou mesmo inferior àquela do suor de um indivíduo adulto, recomendação a ser estudada caso a caso quando o exercício for de alta intensidade e para algumas modalidades, mesmo que em menor duração.

\section{Carboidrato}

A ingestão de carboidratos durante atividades prolongadas, acima de uma hora, melhora o desempenho e pode retardar a fadiga nas modalidades esportivas que envolvem exercícios intermitentes e de alta intensidade. A ingestão de carboidratos previne a queda da glicemia após duas horas de exercício. Existem estudos indicando que uma bebida com 8\% de carboidrato ocasiona maior lentidão na absorção e no esvaziamento gástrico, em comparação com a água e as bebidas que contêm até $6 \%$ de carboidrato. Preferencialmente, deve ser utilizada uma mistura de glicose, frutose e sacarose. O uso isolado de frutose pode causar distúrbios gastrintestinais e retardar sua absorção.

A reposição necessária de carboidratos para manter a glicemia e retardar a fadiga é de 30 a $60 \mathrm{~g}$ por hora, com concentração de 4 a $8 \mathrm{~g} /$ decilitro. Mesmo com uso combinado de diversos carboidratos, sua ingestão não deve exceder $80 \mathrm{~g} / \mathrm{hora}$.

Maior concentração de carboidratos poderá ser ingerida em intervalos maiores de tempo, por exemplo, 20 a 30 minutos, situações vivenciadas em exercícios de baixa intensidade e longa duração, como nas provas de aventura, caminhadas longas, expedições em altitudes elevadas ou mesmo em treinamento de natação.

A utilização de gel energético durante o exercício vem sendo cada vez mais frequente e cumpre o papel na reposição de carboidratos. Porém, seu uso deve ser acompanhado da ingestão regular de água, para que a associação garanta a manutenção do desempenho de um organismo corretamente hidratado.

A seleção da bebida deve ser precedida de leitura cuidadosa de seus componentes. Normalmente, os valores são para porções de $100 \mathrm{ml}$. Assim, uma bebida que contenha $60 \mathrm{~g} / \mathrm{litro}$ terá $6 \mathrm{~g} / 100 \mathrm{ml} \mathrm{de}$ carboidratos. Por força da lei, as informações nutricionais constam do rótulo do produto.

\section{Outros elementos que afetam a eficácia de uma bebida esportiva}

O esvaziamento gástrico é facilitado com a ingestão de líquidos com baixo teor calórico, sendo a absorção intestinal otimizada com líquidos isosmóticos, entre 200 e $260 \mathrm{mosmol} / \mathrm{kg}$. A ingestão de líquidos hipertônicos poderia causar a secreção de água do organismo para a luz intestinal. Vários outros fatores referentes à palatabilidade do líquido afetam a ingestão voluntária, como a temperatura, doçura, intensidade do gosto e acidez, além da sensação de sede e das preferências pessoais.

A ingestão de bebidas geladas influi apenas na palatabilidade, facilitando sua ingestão. Não existem evidências atuais de que bebidas geladas facilitem a absorção da água ou nutrientes que as acompanham. Alguns afirmam que ao chegar ao estômago, a temperatura do líquido ingerido já será próxima da temperatura corporal.

\section{CRIANÇAS E ADOLESCENTES}

Crianças apresentam menor taxa de sudorese quando comparadas com os adultos para esforços que se assemelham em intensidade e duração e em condições térmicas idênticas, em ambiente laboratorial. No entanto, elas se desidratam à semeIhança do adulto. A influência da desidratação no desempenho físico ainda não está bem esclarecida.

Nessa população, a palatabilidade é fator importante no estímulo à reposição de água, visto que pesquisas mostram que sua ingestão voluntária aumenta quando são adicionados sabor: sódio (20 a 25mEq/L) e carboidrato (6\%), evitando a desidratação.

\section{IDOSOS}

Há diminuição de fluxo sanguíneo cutâneo e da taxa de sudorese com o envelhecimento, atenuada naqueles com estilo de vida ativo.

A menor sensibilidade dos barorreceptores faz com que idosos tenham menor percepção da sede e saciedade, expondo-os com mais facilidade às armadilhas da desidratação. A utilização de líquidos aditivados com sódio e carboidratos deve receber análise individual, pois alguns contam com restrições dietéticas decorrentes de doenças crônicas preexistentes.

\section{Recomendações de reposição de líquidos}

Devemos ingerir líquidos antes, durante e após o exercício.

Para garantir que o indivíduo inicie o exercício bem hidratado, recomenda-se que ele beba cerca de 250 a 500ml de água duas horas antes do exercício.

Durante o exercício recomenda-se iniciar a ingestão já nos primeiros 15 minutos e continuar bebendo a cada 15 a 20 minutos. O volume a ser ingerido varia conforme as taxas de sudorese, geralmente entre 500 e $2.000 \mathrm{ml} /$ hora. Se a atividade durar mais de uma hora, ou se for intensa do tipo intermitente mesmo com menos de uma hora, devemos repor carboidrato na quantidade de 30 a $60 \mathrm{~g} \cdot \mathrm{h}^{-1}$ e sódio na quantidade de 0,5 a 0,7g. $\mathrm{l}^{-1}$. A bebida deve estar em temperatura em torno de 15 a $22^{\circ} \mathrm{C}$ e apresentar um sabor de acordo com a preferência do indivíduo, favorecendo a palatabilidade.

Após o exercício, deve-se continuar ingerindo líquidos para compensar as perdas adicionais de água pela diurese e sudorese. Deve-se aproveitar para ingerir carboidratos, em média de $50 \mathrm{~g}$ de glicose, nas primeiras duas horas após o exercício para que se promova a ressíntese do glicogênio muscular e o rápido armazenamento de glicogênio muscular e hepático.

A hiperidratação com líquidos contendo glicerol pode aumentar o risco de hiponatremia pela maior diluição, e a vontade de urinar durante a competição.

Mesmo que boa hidratação durante o exercício prolongado no calor favoreça as respostas termorregulatórias e de performance ao exercício, não podemos garantir que, em situações de extremo estresse térmico, ela seja suficiente para evitar fadiga ou choque térmico. Recomendações específicas foram elaboradas pelo Comitê em Medicina do Esporte e Condicionamento da Academia Americana de Pediatria (tabela 2). O grau de estresse térmico segue o Índice de bulbo úmido e temperatura de globo (IBUTG, ou WBGT, do inglês wet bulb globe temperature), que combina as medidas de temperatura do ar (Tdb), umidade (Twb) e radiação solar (Tg), de acordo com a equação WBGT $=0,7 \mathrm{Twb}+0,2 \mathrm{Tg}+0,1 \mathrm{Td} b$. 
Restrições de atividades físicas de acordo

com os níveis de estresse térmico

\section{IBUTG (OC) Restrições das atividades}

$\overline{<24}$ Qualquer atividade é permitida. Em atividades prolongadas, observar os sinais iniciais de hipertermia e desidratação.

24-25,9 Fazer intervalos mais prolongados na sombra, estimular a ingestão de líquidos a cada $15 \mathrm{~min}$.

26-29 Interromper as atividades daqueles que não estão aclimatizados ao calor ou que apresentam algum outro fator de

risco. Limitar as atividades para todos os outros.

Cancelar qualquer atividade atlética.

American Academy of Pediatrics, 2000.

\section{SUPLEMENTOS ALIMENTARES}

\section{Proteínas}

A ingestão proteica deve ser obtida por uma dieta normal e variada, sendo a suplementação uma forma prática e segura de adequar sua ingestão de boa qualidade e a biodisponibilidade de aminoácidos, para as demandas aumentadas de um atleta em treinamento e competição. O horário e seu tipo é parte de um programa de treinamento e tem por objetivo principal melhorar a recuperação muscular.

Para se estabelecer o valor adequado para ingestão de proteína, é necessário, antes de tudo, determinar, além das características individuais (sexo, idade, perfil antropométrico, estado de saúde, etc.), parâmetros básicos a respeito da atividade física praticada, tais como intensidade, duração e frequência.

Para indivíduos sedentários, recomenda-se a ingestão de 0,8g de proteína por kg/dia. Já indivíduos ativos, com a ingestão de 1,2 a 1,4g/kg/dia, teriam sua demanda atendida. Visando à hipertrofia muscular, atletas ou não teriam suas necessidades atendidas com o consumo máximo de 1,8g/kg/dia contempladas perfeitamente em uma alimentação equilibrada, salvo situações especiais.

Estudos recomendam que o uso dos suplementos proteicos, como a proteína do soro do leite ou a albumina da clara do ovo, deve estar de acordo com a ingestão proteica total. O consumo adicional desses suplementos proteicos acima das necessidades diárias (1,8g/kg/dia) não determina ganho de massa muscular adicional, nem promove aumento do desempenho.

Ingestão proteica, após o exercício físico de hipertrofia, favorece o aumento de massa muscular, quando combinado com a ingestão de carboidratos, reduzindo a degradação proteica. A dose recomendada é de $10 \mathrm{~g}$ de proteínas e $20 \mathrm{~g}$ de carboidratos. Esse consumo deve estar de acordo com a ingestão proteica e calórica total. O aumento da massa muscular ocorre como consequência do treinamento, assim como a demanda proteica, não sendo o inverso verdadeiro.

\section{Aminoácidos}

O consumo de aminoácidos, sob a forma de suplementação, tem sido sugerido como estratégia que visa atender a uma solicitação metabólica específica para as necessidades do exercício. A ingestão de aminoácidos essenciais após o treino intenso, adicionados a soluções de carboidratos, determinaria maior recuperação do esforço seguido de aumento da massa muscular. Do consumo de aminoácidos isolados, apenas os essenciais apresentam alguma sustentação na literatura científica.

Os efeitos da suplementação com BCAA no desempenho esportivo são discordantes e a maioria dos estudos realizados parece não mostrar benefícios, não sendo justificável seu consumo com finalidade ergogênica. Outro ponto que carece de confirmação científica é seu uso com objetivo de melhora do sistema imunológico após atividade física prolongada.

\section{Considerações especiais}

Os aminoácidos de cadeia ramificada (leucina, isoleucina e valina), por serem potentes moduladores da captação de triptofano pelo sistema nervoso central, aumentariam a tolerância ao esforço físico prolongado. Entretanto, esses dados, relatados em alguns estudos, são pouco reprodutivos, não sendo justificável seu consumo com finalidade ergogênica. Outro ponto que carece de comprovação é seu consumo visando aprimoramento da atividade do sistema imunológico após atividade física intensa. Desse modo, recomenda-se que não seja utilizada a suplementação de aminoácidos de cadeia ramificada com finalidade ergogênica.

A glutamina, aminoácido que age como nutriente para as células de divisão rápida, como as intestinais e imunitárias, por exemplo, tem sido utilizada para aumentar a defesa imunológica de atletas, durante períodos de treinamento intenso. Quando a ingestão é oral, o elevado consumo pelas células intestinais inviabiliza sua disponibilidade para outras regiões do organismo, tornando inviável a justificativa de sua suplementação oral, mesmo para os participantes de exercícios físicos muito desgastantes.

Atualmente, não existe evidência científica suficiente demonstrando que a glutamina altere a função imune e previne lesões em atletas saudáveis que consomem níveis adequados de proteínas, o que torna sua suplementação necessária apenas em casos em que a avaliação individual assim indicar.

A ornitina e a arginina são aminoácidos que produzem maior secreção de hormônio de crescimento quando oferecidos através de infusão intravenosa, sendo, entretanto, seu consumo por via oral ineficaz. Não é recomendada a suplementação destes aminoácidos.

\section{Creatina}

A creatina tem sido apontada como o suplemento nutricional de maior eficiência na melhora do desempenho em exercícios de alta intensidade e no aumento de massa muscular. Já seu uso como recurso ergogênico em atividades físicas prolongadas não encontra nenhum suporte na literatura científica. A melhora, ou não, do desempenho em exercícios com predominância aeróbia é pouco documentada.

Embora com resultados ainda controversos, muitos estudos têm sugerido que a creatina teria efeito ergogênico em indivíduos nos quais se constata diminuição de aporte da creatina exógena alimentar, como os vegetarianos e os indivíduos idosos, sendo somente para estes casos específicos, após boa análise do profissional especializado, médico e/ou nutricionista, justificável seu uso, embora, ainda, com fraco grau de recomendação.

Somente para atletas competitivos de eventos de grande intensidade e curta duração, ou sejam, atividades nas quais predomina a utilização de fosfagênios, sempre em caráter excepcional, seu uso é permitido. Portanto, mesmo nesses casos, a recomendação é 
a de que em geral não se deve usar a suplementação de creatina, sendo seu uso aceito em raras ocasiões. Para os demais desportistas fica estabelecida a recomendação de nunca usar.

Desse modo, recomenda-se que a utilização da creatina como suplemento, com finalidade ergogênica, seja analisada individualmente, caso a caso, de acordo com as necessidades analisadas.

\section{$\beta$-hidroxi- $\beta$-metilbutirato}

O uso de $\beta$-hidroxi- $\beta$-metilbutirato (HMB) tem sido cogitado como um potencial agente para o aumento da força e massa magra corporal, por promover ação anticatabólica. Porém, ainda faltam estudos científicos que comprovem de maneira inequívoca a eficácia do suplemento nessa ação ergogênica, a não ser em algumas situações específicas, como é o caso de populações de idosos que participam de programas de exercícios físicos visando o ganho de força muscular.

Para a população em geral, mesmo quando se trata de atletas de competição, não existe recomendação para seu uso, devendo prevalecer a orientação de que não se deve usar.

\section{SUBSTÂNCIAS LÍCITAS E ILÍCITAS}

Substâncias ilícitas são aquelas cuja utilização, de acordo com a Agência Mundial Antidoping (WADA) e o Comitê Olímpico Internacional (COI), caracteriza uma infração de códigos éticos e disciplinares, podendo ocasionar sanções aos atletas, bem como aos seus técnicos, médicos e dirigentes. A lista atualizada de substâncias e métodos proibidos pode ser obtida no início de janeiro de cada ano, no site da Agencia Mundial Antidoping (www.wada. awa.org) e esclarecimentos adicionais pelo e-mail antidoping@ cob.org.br

\section{Autorização para uso de substâncias restritas e proibidas}

Existem exceções a serem consideradas, visando às eventuais solicitações de autorizações para uso terapêutico de fármacos que constam na listas de substâncias restritas e proibidas. São exemplos disso o uso de beta2-agonistas e corticosteroides por asmáticos; o uso de diuréticos por portadores de hipertensão arterial sistêmica; e o uso de insulina por diabéticos. Nesses casos, deve ser encaminhada solicitação formal de permissão especial à confederação ou federação do esporte do atleta solicitante.

Uma vez feita, a solicitação poderá ser deferida após análise do diagnóstico e da indicação do fármaco. Para essa finalidade, existem formulários especiais de indicação do uso terapêutico (TUE), disponíveis como anexo na cartilha, disponível no site do COB.

O documento solicitando permissão especial deve ser encaminhado à autoridade médica competente 21 dias antes da competição, para que seja devidamente avaliado pela Agência Brasileira Antidoping, que poderá aprová-la, ou não, para eventos nacionais e orientar nos casos de eventos no Exterior.

\section{Algumas considerações adicionais:}

a) S3: Beta-2-agonistas, que são drogas proibidas com exceção do formoterol, salbutamol, salmeterol e terbutalina. As demais drogas beta-2- agonistas exigem a solicitação de permissão especial por meio do formulário abreviado (aTUE). Convém ressaltar que concentrações de salbutamol superiores a $1.000 \mathrm{ng} / \mathrm{ml}$ resulta- rão sempre em resultado analítico adverso, ou seja, positivo para doping.

b) S5: Diuréticos, que são considerados agentes mascarantes e sua utilização exige permissão especial autorizada, obtida por meio do TUE.

c) S8: Substâncias antes permitidas, que foram incluídas no programa de monitoramento de 2008, portanto atualmente proibidas: bupropiona, cafeína, fenilefrina, fenilpropranolamina, pipradol, pseudoefedrina, sinefrina. São permitidas: adrenalina associada com agentes anestésicos para uso local (ex.: nasal, oftálmico); catina apenas quando a concentração na urina for inferior a 5 microgramas/L; efedrina e metilefedrina apenas quando a concentração for inferior a 10 micro gramas/L.

d) S9: Glicocorticoides (via oral, retal ou endovenosa), cujo uso exige permissão especial concedida, via TUE. O uso em todas as outras rotas (intra-articular, periarticular, peritendinosa, epidural, intradermal e inalatória) exige permissão obtida por meio do formulário abreviado (aTUE). O uso dermatológico, inclusive iontoforese e fonoforese, é permitido. O mesmo acontece com o uso nasal, oftalmológico, gengival e perianal.

e) Álcool e betabloqueadores são substâncias permitidas em todos os esportes, exceto em alguns que fazem parte de listas especiais. A lista referente ao álcool consta na página 38 e a referente aos betabloqueadores na página 39 da cartilha do COB.

f) Relação de alguns fármacos permitidos: para tratamento de asma brônquica, a lista de fármacos permitidos está na página 45; a lista de contraceptivos permitidos na página 47; cremes dermatológicos permitidos, na página 47 da cartilha COB.

g) Aminoácidos, sais minerais, vitaminas: são permitidos, mas cabe a ressalva de que o uso exige cautela, tendo em vista a possibilidade de que conste intencionalmente na composição substancia proibida não referida no rótulo. Existe ainda a possibilidade de que a substância proibida conste no produto por contaminação.

\section{Substâncias proibidas (ilícitas)}

\section{S1. Agentes Anabólicos.}

1. Esteroides androgênicos anabólicos (EAA):

a. EAA exógenos.

b. EAA endógenos.

2. Outros agentes anabólicos, dentre outros, clembuterol, moduladores seletivos de receptores, androgênicos (MSRAs, "SARMs"), tibolona, zeranol, zilpaterol.

\section{S2. Hormônios, Substâncias Afins e seus Fatores de Liberação:}

1. Eritropoietina (EPO);

2. Hormônio do crescimento humano (hGH), fator de crescimento semelhante à insulina (IGF-1) e fatores de crescimento mecânicos (MGFs);

3. Gonadotrofinas (hCG,LH etc.) proibidas somente em homens;

4. Insulinas;

5. Corticotrofinas;

6. Outras substâncias com estrutura química similar ou efeito biológico(s) similar(es). 
S3. Beta-2- Agonistas: Todos os beta-2-agonistas, tanto isômeros D- como L-, são proibidos.

\section{S4. Agentes com Atividade Anti-Estrogênica.}

1. Inibidores da aromatase, dentre outros, anastrozola, letrozola, aminoglutetimida, exemestano, formestano, testolactona.

2. Moduladores de receptor seletivo a estrógenos (SERMs), dentre outros, raloxifeno, tamoxifeno, toremifeno.

3. Outras substâncias antiestrogênicas, dentre outras, clomifeno, ciclofenila, fulvestranto.

4. Agentes modificadores da função(ões) da miostatina, dentre outros, inibidores da miostatina.

S5. Diuréticos e Outros Agentes Mascarantes: Diuréticos, epitestosterona, probenecida, inibidores da alfa redutase, (como a finasterida, dutasterida), expansores de plasma (como a albumina, o dextran e o hidroxietilamido) e outras substâncias com efeito(s) biológico(s) similar(es).

\section{Métodos proibidos}

\section{M1. Aumento do Carreamento de Oxigênio:}

a. Doping sanguíneo, incluindo o uso de sangue autólogo, homólogo ou heterólogo, ou de produtos contendo glóbulos vermelhos de qualquer origem.

b. Aumento artificial da captação, transporte ou aporte de oxigênio, dentre outros, perfluoroquímicos, efaproxiral (RSR 13) e produtos à base de hemoglobina modificada (como substitutos de sangue com base em hemoglobina e produtos com hemoglobina microencapsulada).

\section{M2. Manipulação Química e Física:}

1. Manipular ou tentar manipular, visando alterar a integridade e validade das amostras coletadas no controle de dopagem, como, dentre outras possibilidades, a substituição e/ou alteração da urina.

2. Infusões intravenosas são proibidas. Em caso de emergência médica em que o método for necessário, Isenção de Uso Terapêutico retroativa será necessária..

M3. Doping Genético: $\bigcirc$ uso não terapêutico de células, genes, elementos genéticos, ou a modulação da expressão genética, que tenham a capacidade de aumentar o desempenho do atleta, é proibido.

\section{Substâncias e métodos proibidos em competição.}

Além das categorias S1 a S5 e M1 a M3, definidas anteriormente, que são proibidas em competição, devem ser consideradas:

\section{Substâncias Proibidas em Geral:}

S6. Estimulantes: Todos os estimulantes são proibidos, incluindo seus isômeros óticos (D- e L-) quando relevantes, exceto derivados de imidazol para uso tópico e aqueles estimulantes incluídos no programa de monitoramento de 2008.

S7. Narcóticos: Buprenorfina, dextromoramida, diamorfina (heroína), fentanil e seus derivados, hidromorfona, metadona, morfina, oxicodona, oximorfona, pentazocina e petidina.
S8. Canabinoides: Canabinoides (Exemplos: haxixe e maconha).

S9. Glicocorticosteroides: Todos os glicocorticosteroides são proibidos quando administrados por via oral, retal, intramuscular ou endovenosa. Seu uso terapêutico requer a aprovação de uma Isenção de Uso Terapêutico (TUE).

\section{Substâncias Proibidas em Determinados Esportes:}

P1. Álcool: Álcool (etanol) é proibido somente em competição, nos esportes abaixo relacionados. A detecção será feita por análise respiratória e/ou pelo sangue. O limite permitido (em valores hematológicos) por cada Federação ou Confederação está indicado entre parênteses.

\begin{tabular}{l|r|r}
\hline Aeronáutica & FAI & $(0,20 \mathrm{~g} / \mathrm{L})$ \\
\hline Arco e flecha & FITA, IPC & $(0,10 \mathrm{~g} / \mathrm{L})$ \\
\hline Automobilismo & FIA & $(0,10 \mathrm{~g} / \mathrm{L})$ \\
\hline Boliche & CMSB, IPC & $(0,10 \mathrm{~g} / \mathrm{L})$ \\
\hline Lancha de potência & UIM & $(0,30 \mathrm{~g} / \mathrm{L})$ \\
\hline Karatê & WKF & $(0,10 \mathrm{~g} / \mathrm{L})$ \\
\hline Motociclismo & FIM & $(0,10 \mathrm{~g} / \mathrm{L})$ \\
\hline Pentatlo Moderno (em tiro) & UIPM & $(0,10 \mathrm{~g} / \mathrm{L})$ \\
\hline
\end{tabular}

P2. Betabloqueadores - Quando não especificados, betabloqueadores são proibidos somente em competição nos seguintes esportes:

\begin{tabular}{l|r}
\hline Aeronáutica & FAI \\
\hline Arco e flecha (proibido também fora de competição) & FITA, IPC \\
\hline Automobilismo & FIA \\
\hline Bilhar & WCSB \\
\hline Bobsleigh & FIBT \\
\hline Boliche & CSMB, IPC \\
\hline Boliche com 9 pinos & FIQ \\
\hline Bridge & FMB \\
\hline Curling & WCF \\
\hline Esqui/Snowboarding (salto com esqui e estio livre em & FIS \\
snow board) & FIG \\
\hline Ginástica & UIM \\
\hline Lancha de potência & FILA \\
\hline Luta & FIM \\
\hline Motociclismo & UIPM \\
\hline Pentatlo Moderno (para disciplinas envolvendo tiro) & ISSF, IPC \\
\hline Tiro (proibido também fora de competição) & ISAF \\
\hline Vela (somente para os timoneiros em match race) & \\
\hline
\end{tabular}

Substâncias Especificadas: Beta-2-agonistas, quando usados por inalação, exceto o salbutamol superior a 1000ng/ml e clembuterol; Inibidores de alfa-redutase e probenecida; Catina, cropropamida, crotetamida, efedrina, etamivan, famprofazona, fenprometamina, heptaminol, isometepteno, levmetanfetamina, meclofenoxato, p-metilanfetamina, metilefedrina, niquetamida, norfenefrina, octopamina, ortetamina, oxilofrina, propilexedrina, selegilina, sibutramina, tuaminoheptano, e qualquer estimulante não mencionado especificamente na seção S6, quando o atleta preencher as condições lá descritas; Canabinoides; Glicocorticoesteroides; Álcool; Betabloqueadores. 


\section{LEITURA RECOMENDADA PRIMEIRA PUBLICAÇÃO}

\section{Modificações dietéticas}

Beard J, Tobin B. Iron status and exercise. Am J Clin Nutr 2000;72: S594-7.

Bowden VL, McMurray RG. Effect of training status on the metabolic responses to high carbohydrate and high fat meals. Int J Sport Nutr Exerc Metab 2000;10:16-27.

Brun JF, Bouchahda C, Chaze D, Benhaddad AA, Micallef JP, Mercier J. The paradox of hematocrit in exercise physiology: which is the "normal" range from an hemorheologist's viewpoint? Clin Hemorheo Microcirc 2000;22:287-303.

4. Burke LM, Cox GR, Culmmings NK, Desbrown B. Guidelines for daily carbohydrate intake: do athletes achieve them? Int J Sports Med 2001; 31:267-99

Burke LM. Energy needs of athletes. Can J Appl Physiol 2001;26:202-19.

6. Carrithers JA, Williamson DL, Gallagher PM, Godard MP, Schulze KE, Trappe SW. Effects of post-exercise carbohydrate-protein feeding on muscle glycogen restoration. J Appl Physiol 2000;88:1976-82.

Clarkson PM, Thompson HS. Antioxidants: what role do they play in physical activity and health? Am J Clin Nut 2000;72:5637-46.

8. Faff J. Effects of the antioxidant supplementation in athletes on the exercise-induced oxidative stress. Biology of Sport 2001;18:3-20

Garlick PJ, McNurlan MA, Ballmer PE. Influence of dietary protein intake on whole-body protein turnover in humans. Diabetes Care 1991; 14:1189-98.

10. Ginsburg GS, O'Toole M, Rimm E, Douglas PS, Rifai N. Gender differences in exercise-induced changes in Sex hormone levels and lipid peroxidation in athletes participation in the Hawaii Ironman triathlon. Ginsburg-gender and exercise induced lipid peroxidation. Clin Chim Acta 2001;305:131-9.

11. Glesson M, Bishop NC. Elite athlete immunology: importance of nutrition. Inter J Sports Med 2000;21:544-50.

12. Hassapidou MN, Manstrantoni A. Dietary intakes of elite female athletes in Greece. J Hum Nutr Diet 2001;14:391-6.

13. Jeukendrup AE, Saris WHM, Wagenmakers AJM. Fat metabolism during exercise: a review. Int J Sport Med 1998;19:371-9.

14. Kiens B. Diet and training in the week before competition. Can J Appl Physiol 2001;26:S56-63.

15. Lemon PW Effects of exercise on dietary protein requirements. Int I Sport Nutr 1998:8:426-47.

16. Manore MM. Effect of physical activity on thiamine, riboflavin, and vitamin B-6 requirements. Am J Clin

. Maughan RJ. Role of micronutrients in sport and physical activity. Br Med Bull 1999;55:683-90.

18. Maughan R. The athlete's diet: nutritional goals and dietary strategies. Proc Nutr Soc 2002;61:87-96.

9. McConell G, Snow RJ, Projetto J, Hargreaves M. Muscle metabolism during prolonged exercise in humans: influence of carbohydrate availability. J Appl Physiol 1999;87:1083-6.

20. Micheletti A, Rossi A, Rufini S. Zinc status in athletes: relation to diet and exercise. Eur J Physio 2002:443:791-7.

21. Nakamura M, Brown J, Miller WC. Glycogen depletion patterns in trained rats adapted to a high-fat or high carbohydrate diet. Int J Sports Med 1998;19:419-24

22. Nieman DC, Pedersen BK. Exercise and immune function - recent developments. Sports Med 1999:27:73-80.

23. Nutrition and athletic performance. Med Sci Sports Exerc 2000;32:2130-45.

24. Pendergast DR, Leddy JJ, Venkatraman JT. A perspective of fat intake in athletes. J Am Coll Nutr 2000;19:345-50

25. Poortmans R, Dellalieux O. Do regular high protein diets have potential health risks on kidney function in athletes? Int J Sports Med 2000:20:28-38.

26. Sacheck JM, Decker EA, Clarkson PM. The effect of diet on vitamin E intake and oxidative stress in response to acute exercise in female athletes. Eur J Appl Physiol 2000:83:40-6.

27. Schroder H, Navarro E, Mora J, Seco J, Torregrosa JM, Tramullas A. The type, amount, frequency and timing of dietary supplement use by elite players in the First Spanish Basketball League. J Sports Sc 2002; 20:353-8

28. Sen CK. Antioxidants in exercise nutrition. Sports Med 2001;31:891-908.

29. Spivak JL. Erythropoietin use and abuse: when physiology and pharmacology collide. Adv Exp Med Biol 2001; $502: 207-24$

30. Stannard SR, Constantini NW, Miller JC. The effect of glycemic index on plasma glucose and lactate levels during incremental exercise. Int I Sport Nutr Exerc Metab 2000;10:51-61.

31. Tauler P, Aguilo A, Fuentespina E, Tur JA, Pons A. Diet supplementation with vitamin E, vitamin C and beta-carotene cocktail enhances basal neutrophil antioxidant enzymes in athletes. Eur J Physiol 2002;443: 791-7.

32. Thompson JL. Energy balance in young athletes. Int J Sport Nutr 1998; 8:160-74.

33. Van Erp-Baart AM, Saris WH, Binkhorst RA, Vos JA, Elvers JW. Nationwide survey on nutritional habits in elite athletes. Part 1. Energy, carbohydrate, protein and fat intake. Int I Sports Med 1989;10:53-10.

34. Vasankari T, Kujala U, Sarnas S, Ahotupa M. Effects of ascorbic acid and carbohydrate ingestion on exercise induced oxidative stress. J Sports Med Phys Fitness 1998;38:281-5.

35. Wigernaes I, Hostmark AT, Stromme SB, KierulfP, Birkeland K. Active recovery counteracts the post-exercise rise in plasm-free fatty acids. Int I Sport Nutr Exerc Metab 2000;10:404-14

36. Xia G, Chin MK, Girandola RN, Liu RY. The effect of diet and supplements on a male world champion lightweight rower. I Sports Med Phys Fitness 2001;41:223-8.

7. Zachwieja JJ, Ezell DM, Cline AD, Ricketts JC, Vicknair PC, Schorle SM, et al. Short-term dietary energy restrition reduces lean body mass but not performance in physically active men and women. Int I Sports Med 2001;22:310-16.

II. Reposição hídrica

2000;106:158-9.

American College of Sports Medicine. ACSM Position Stand on Exercise and Fluid Replacement Med Sci Sports Exerc 1996;28:i-vii.

American College of Sports Medicine. Position Stand: Heat and cold illnesses during distance running Med Sci Sports Exerc 1996;28:- $-x$

Below PR, Mora-Rodriguez R, Gonzalez-Alonso J. Fluid and carbohydrate ingestion independently improve Below PR, Mora-Rodriguez R, Gonzalez-Alonso J. Fluid and carbohydrate ingestion 10 ,
performance during $1 \mathrm{~h}$ of intense exercise. Med Sci Sports Exerc 1995;27:200-10

Berry PL, Belsha CW. Hyponatremia. Pediatr Clin North Am 1990;37: 351-163.

Clowes GHA, O'Donnel TF Jr. Heat stroke. N Engl J Med 1974;291: 564-7.

Coggan AR, Coyle EF. Carbohydrate ingestion during prolonged exercise: effects on metabolism and performance. Exerc Sport Sci Rev 1991; 19:1-40.

Coyle EF, Montain SJ. Benefits of fluid replacement with carbohydrate during exercise. Med Sci Sports Exerc 1992;24:S324-30.

Coyle EF, Coggan AR, Hemmert MK, IVy JL. Muscle glycogen utilization during prolonged strenuous exercise when fed carbohydrates. J Appl Physiol 1986;61:165-72

10. Coyle EF. Cardiovascular drift during prolonged exercise and the effects of dehydration. Int J Sports Med 1998:19:5121-4

11. Crane RK. The gradient hypothesis and other models of carrier-mediated active transport. Rev Physiol Biochem Pharmacol 1977;78:100-59.

12. Davies MJ, Lamb DL, Pate RR, Slentz CA, Burgess WA, Bartoli WP. Carbohydrate-electrolyte drinks: effects Davies MJ, Lamb DL, Pate RR, Slentz CA, Burgess WA, Bartoli WP. Carbo
on endurance cycling in the heat. Am J Clin Nutr 1988:48:1023-30.

13. Fortney $S M$, Wenger CB, Bove JR, Nadel ER. Effect of blood volume on forearm venous and cardiac stroke volumes during exercise. J Appl Physiol 1981;55:884-90.

14. Gisolfi CV, Copping JR. Thermal effects of prolonged treadmill exercise in the heat. Med Sci Sports Exerc 1974;6:108-13.

15. Gisolfi CV, Summers RW, Schedl HP, Bleiler TL, Opplinger RA. Human intestinal water absorption: direct vs indirect measurements. Am J Physiol 1990;258:G216-22

16. Greenleaf JE, Sargent R. Voluntary dehydration in man. J Appl Physiol 1965;20:719-24.

17. Gruskin AB, Baluarte HJ, Prebis JW, Polinski MS, Morgenstern BZ, Perlmen SA. Serum sodium abnormalities in children. Pediatr Clin North Am 1982;29:907-32.

18. Hamilton MT, Gonzalez-Alonso J, Montain SJ, Coyle EF. Fluid replacement and glucose infusion during exercise prevents cardiovascular drift. J Appl Physiol 1991:71:871-7.

19. Horswill CA. Effective fluid replacement. Int J Sport Nutr 1998;8:175-95.

20. Hubbard RW, Sandick BL, Matthew WT, Francesconi RP, Sampson JB, Durkot MJ, et al. Voluntary dehydra- tion and alliesthesia for water. J Appl Physiol (Respirat Environ Exercise Physiol) 1984;57:868-75

I Ivy JL, Lee MC, Brozinick JT, Reed MJ. Muscle glycogen storage after different amounts of carbohydrate ingestion. J Appl Physiol 1988;65: 2018-23.

22. Leiper JB, Maughan RJ. Absorption of water and electrolytes from hypotonic, isotonic, and hypertonic solutions. J Physiol 1986;373:90.

Leiper JB. Gastric emptying and intestinal absorption of fluids, carbohydrates, and electrolytes. In: Sports Drinks: Basic and Practical Aspects, 2001;89-128.

24. Maughan RJ, Leiper JB, Shirreffs SM. Factors influencing the restoration of fluid and electrolyte balance after exercise in the heat. Br J Sports Med 1997;31:175-82.

25. Meyer F, Bar-Or O. Fluid and electrolyte loss durante exercise: the pediatric angle." Leading article." Sports Med 1994;18:4-9.

26. Meyer F, Bar-Or O, MacDougall D, Heigenhauser G. Sweat electrolyte loss during exercise in the heat effects of gender and level of maturity. Med Sci Sports Exerc 1992;24:776-81.

27. Montain SJ, Coyle EF Fluid ingestion during exercise increases skin blood flow independent of increases in blood volume. J Appl Physiol 1992;73:903-10.

28. Nadel ER, Fortney SM, Wenger CB. Effect of hydration state on circulatory and thermal regulations.J App Physiol 1980:49:715-21

29. Noakes TD, Goodwin N, Rayner BL, Branken T, Taylor RKN. Water intoxication: a possible complication during endurance exercise. Med Sci Sports Exerc 1985;17:370-5.

30. Passe HD. Physiological and psychological determinants of fluid intake. In: Sports Drinks: Basic and Practical Aspects, 2001;45-87.

31. Pitts GC, Johnson RE, Consolazio FC. Work in the heat as affected by intake of water, salt, and glucose. Am J Physiol 1944;142:253-9.

32. Rivera-Brown AM, Gutiérrez R, Gutiérrez JC, Frontera WR, Bar-Or O. Drink composition, voluntary drinking, and fluid balance in exercising, trained, heat-acclimatized boys. J Appl Physiol 1999;86:78-84.

3. Rothstein A, Adolph EF, Wills JH. Voluntary dehydration. New York: Interscience, 1947.

34. Saltin B. Circulatory response to submaximal and maximal exercise after thermal dehydration. J App Physiol 1964;19:1125-32.

35. Sawka MN, Gonzalez RR, Young AJ, Dennis RC, Valeri CR, Pandolf KB. Control of thermoregulatory sweating during exercise in the heat. Am J Physiol 1989;257:R311-6.

36. Sawka MN, Young AJ, Francesconi RP, Muza SR, Pandolf KB. Thermoregulatory and blood responses during exercise and graded hypohydration levels. J Appl Physiol 1985;25:149-52.

37. Sawka MN Pandolf KB. Effect of body water loss on physiological function and exercise performance In: Gisolfi CV, Lamb DR, eds. Perspectives in Exercise and Sport Medicine. Fluid Homeostasis during Exercise. Indianapolis: Benchmark Press Inc, 1990; 1-30.

38. Sawka MN, Young AJ, Latzka WA, Neufer PD, Quigley MD, Pandolf KB. Human tolerance to heat strain during exercise: influence of hydration. J Appl Physiol 1992;73:368-75

39. Sawka MN. Physiological consequences of hypohydration: exercise, performance, and thermoregulation. Med Sci Sports Exerc 1992;24:657-70

40. Senay L. Temperature regulation and hypohydration: a singular view. J Appl Physiol 1979;47:1-7.

41. Shapiro Y, Moran D, Epstein Y. Acclimatization strategies - Preparing for exercise in the heat. Int J Sports Med 1998;19:S161-3.

42. Shi X, Gisolfi CV. Fluid and carbohydrate replacement during intermittent exercise. Sports Med 1998;25:157-72.

43. Shirreffs SM, Maughan RJ. Volume repletion following exercise-induced volume depletion in man: replacement of water and sodium losses. Am J Physiol 1998:43:F868-75.

44. Szlyk PC, Sils IV, Francesconi RP, Hubbard RW, Armstrong LE. Effects of water temperature and flavoring on voluntary dehydration in men. Physiol Behav 1989;45:639-47.

45. Wilk B, Bar-Or O. Effect of drink flavor and NaCl on voluntary drinking and hydration in boys exercising in the heat. J Appl Physiol 1996; 80:1112-17.

\section{Suplementos alimentares}

Butterfield G. Amino acids and high protein diets. In: Perspectives in exercise science and sports medicine: Ergogenics-enhancement of performance in exercise and sport. Lamb DR, Williams MH, eds. Miami: Cooper Publishing, 2001

2. Casey A, Greenhaff PL. Does dietary creatine supplementation play a role in skeletal muscle metabolism and performance? Am J Clin Nutr 2000;72:5607-17.

Chrusch MJ, Chilibeck PD, Chad KE, Davison KS, Burke DG. Creatine supplementation combined with resistance training in older men. Med Sci Sports Exerc 2001;33:2111-17.

David JM, Alderson NL, Welsh RS. Serotonin and central nervous system fatigue: nutritional considerations. Am J Clin Nutr 2000;72:573-8

Hargreaves MH, Snow R. Amino acids and endurance exercise. Int J Sport Nutr Exerc Metab 2001;11:133-

Harris, RC, Soderlund K, Hultman E. Elevation of creatine in resting and exercise muscle of normal subjects by creatine supplementation. Clin Sci 1992:83:367-74

Hultman E, Soderlund K, Timmons A, Cederblad G, Greenhaff PL. Muscle creatine loading in men. J App Physiol 1996;81:232-7.

8. Paul GL Gautsch TA Layman DK Amino acid and protein metabolism during exercise and recovery In: Wolinsky I, ed. Nutrition in Exercise and Sport. Florida: CRC Press, 1998

DKe and Sport. Florida. CRC Press, 1998 . Persky AM, Brazeau GA. Clin

10. Poortmans JR, Francaux M. Adverse effects of creatine supplementation. Sports Med 2000;30:155-70

1. Rasmussen BB, Tipton KD. Miller SL, Wolf SE, Wolfe RR. An oral essential amino acid-carbohydrate supplement enhances muscle protein anabolism after resistance exercise. J Appl Physiol 2000;88:386-92.

Slater GJ, Jenkins D. $\beta$-hydroxy- $\beta$-metilbutyrate (HMB) supplementation and the promotion of muscle growth and strength. Sports Med 2000; 30:105-16.

13. Tarnopolsky MA. Protein and physical performance. Curr Opin Clin Nutr Metab Care 1999;2:533-7.

4. Terjung RL, Clarkson P, Eichner ER, Greenhaff PL, Hespel PJ, Israel RG, et al. American College of Sports Medicine roundtable. The physiological and health effects of oral creatine supplementation. Med SC Sports Exerc 2000;32:706-17.

15. Tipton KD, Wolfe RR. Exercise, protein metabolism, and muscle growth. Int J Sport Nutr Exerc Metab 2001;11:109-32.

Wagenmakers AJM. Amino acid supplements to improve athletic performance. Curr Opin Clin Nutr Metab Care 1999;2:539-44.

\section{Drogas lícitas e ilícitas}

American College of Sports Medicine Position Stand on the Use of Blood Doping as an Ergogenic Aid. Med Sci Sports Exerc 1996;28

American College of Sports Medicine. Use of anabolic androgenic steroids in sport. Med Science Sport Exer 1987;19:534-9.

Comitê Olímpico Brasileiro. Http://www.cob.org.br

4 De Rose EH, Nóbrega ACL. Drogas Lícitas e llícitas. In: Ghorayeb N, Barros T. O Exercício. São Paulo: Atheneu, 1999.

Eichner ER. Ergogenic Aids: What athletes are using - and why Phys Sports Med 1997.25.97.

6. Feder MG, De Rose EH. O uso de medicamentos no esporte. Rev Bras Med Esporte 1996?

Gruber AJ, Pope HG Jr. Psychiatric and medical effects of anabolic-androgenic steroid use in women Psychoter Psychosom 2000;69:19-26.

International Olympic Committee - Antidoping code. Http://www. olympic.org?uk/organisation/comissions/medical/antidoping ukasp

International Olympic Committee wwwolympicorg/uk/news/publications/press uk.asp? release $=113$

10. International Olympic Committee wwwolympicorg/uk/news/publications/press ukasp? release $=173$

11. International Olympic Committee. Http://www.olympic.org/uk/news/publications/press. uk. asp?rel

12. International Olympic Committee. Http://multimedia.olympic.org/pdf/en report 21.pdf

13. International Olympic Committee. Http://multimedia.olympic.org/pdf/en report 22.pd

14. Pardos CL, Gallego VP, Rio-Mayor MJ, Martin AV. Dopaje sanguineo y Eritropoietina. Archivos de Medicina Del Deporte 1998;64:145-8.

15. Stephen MB, Olsen C. Ergogenic supplements and health risk behaviors. J Fam Pract 2001:50:696-9. 


\section{LEITURA RECOMENDADA PRIMEIRA REVISÃO}

\section{Modificações dietéticas}

Swinburn B, Ravussin E. Energy balance or fat balance? Am J Clin Nutr. 1993;57(suppl):766S-71S. Montoye HJ, Kemper HCG, Saris WHM, Washburn RA. Measuring physical activity and energy expenditure. Champaign (IL): Human Kinetics Ltd; 1996.

Katch Fl, McArdle WD. Introduction to nutrition, exercise, and health. $4^{\text {th }}$ ed. Philadelphia (PA): Lea \&Febiger; 1993

Grandjean AC. Diets of elite athletes: has the discipline of sports nutrition made an impact? Nutr.1997;127(suppl):8745-75.

Position of the American Dietetic Association: Nutrition Intervention in the treatment of anorexia nervosa, bulimia nervosa, and binge eating. J Am Diet Assoc. 1994;94:902-7.

Brownell KD, Rodin J, Wilmore JH. Eating, body weight, and performance in athletes: disorders of modern society. Philadelphia (PA): Lea \& Febiger; 1992.

Sundgot-Borgen J. Eating disorders. In: Berning JR, Steen SN, eds. Nutrition for sport and exercise Gaithersburg (MD): Aspen Publishers; 1998:187-203.

Thompson RA, Sherman RT. Helping athletes with eating disorders. Champaign (IL): Human Kinetics Publishers; 1993.

Position of the American Dietetic Association and Dietitians of Canada: Nutrition and Women's Health Journal of the American Dietetic Association June 2004; 6:984-1001.

Horowitz JF, Mora-Rodriguez R, Byerley LO, Coyle EF. Substrate metabolism when subjects are fed carbohydrate during exercise. Am J Physiol. 1999; 276:E828-35.

Burke LM, Cox GR, Cummings NK, Desbrow B. Guidelines for daily carbohydrate intake. Do athletes achieve them? Sports Med. 2001;31(4):267-99.

Zalcman I, Guarita HV, Juzwiak CR, Crispim C, Antunes HK, Edwards B, Tufik S, Mello MT de . Nutritional status of adventure racers. Nutrition. 2007; 23:404-411.

Zalcman I, Crispim C, Juzwiak CR, Antunes HK, Edwards B, Waterhouse J, Tufik S, Mello MT de . Nutritional intake during a simulated adventure race. International Journal of Sport Nutrition and Exercise Metabolism, v. 18, p. 152-168, 2008

Jeukendrup, A.E. Carbohydrate intake during exercise and performance. Nutrition. 2004; 20, 669-677. Wilson J, Wilson GJ. Contemporary Issues in Protein Requirements and Consumption for Resistance Trained Athletes. JISSN. 2006;3(1):7-27.

Lemon PW. Effects of exercise on dietary protein requirements. Int J Sport Nutr 1998;8:426-47.

Davis JM, Bailey SP. Possible mechanisms of central nervous system fatigue during exercise. Med Sci Sports Exerc. 1997;29:45-57.

Lambert, $C$., et al. Macronutrient considerations for the sport of bodybuilding. Sports Medicine. 2004 34:317-27.

Tarnopolsky, M. Protein requirements for endurance athletes. Nutrition 2004; 20:662-668

Butterfield GE. Whole-body protein utilization in humans. Med Sci Sports Exerc. 1987;19(suppl):S157-65.

Horvath PJ, Eagen CK, Ryer-Calvin SD, Pendergast DR. The Effects of Varying Dietary Fat on the Nutrient Intake in Male and Female Runners. J. Am. Coll. Nutr. 2000:19;42-51.

\section{Reposição hídrica}

American College of Sports Medicine: Sawka MN, Burke LM, Eichner ER, Maughan RJ, Montain SJ, Stachenfeld NS. American College of Sports Medicine Position Stand: Exercise and fluid replacement. Med Sci Sports Exerc. 2007; 39:377-90.

National Athletic Trainers' Association (NATA). Position Statement: fluid replacement for athletes. J Athl Train 2000; 35(2): $212-224$

Sawka MN. Physiological consequences of hypohydration: exercise, performance, and thermoregulation Med Sci Sports Exerc. 1992;24:657-70.

Nadel ER, Fortney SM, Wenger CB. Effect of hydration state on circulatory and thermal regulations. Appl Physiol 1980;49:715-21.

Coyle EF. Cardiovascular drift during prolonged exercise and the effects of dehydration. Int J Sports Med 1998;19:5121-4.

Nadel ER, Fortney SM, Wenger CB. Effect of hydration state on circulatory and thermal regulations. Appl Physiol 1980:49:715-21.

Lieberman HR. Hydration and cognition: a critical review and recommendations for future research. $J$ Am Coll Nutr. 2007; 26(5): 555S-561S.

Murray B. Hydration and physical performance. J Am Coll Nutr. 2007; 26(5 Suppl):542S-548S.

Judelson DA, Maresh CM, Anderson JM, Armstrong LE, Casa DJ, Kraemer WJ, Volek JS. Hydration and muscular performance: does fluid balance affect strength, power and high-intensity endurance? Sports Med. 2007; 37(10):907-21

Baker LB, Conroy D, Kenney LW. Dehydration impairs vigilance-related attention in male basketball players. Med Sci Sports Exerc. 2007a; 39(6):976-983.

Baker LB, Dougherty KA, Chow M, Kenney LW. Progressive dehydration causes a progressive decline in basketball skill performance. Med Sci Sports Exerc. 2007b; 39(7):1114-1123.

Below PR, Mora-Rodriguez R, Gonzalez-Alonso J, Coyle E. Fluid and carbohydrate ingestion independently improve performance during 1 h of intense exercise. Med Sci Sports Exerc.1995; 27: 200-210. Hubbard RW, Sandick BL, Matthew WT, Francesconi RP, Sampson JB, Durkot MJ, et al. Voluntary dehydration and alliesthesia for water. J Appl Physiol (Respirat Environ Exercise Physiol) 1984;57:868-75.

Passe D. Physiological and Psychological determinants of fluid intake. Sports Drinks. In. Maughan R; Murray, R. (Ed). Boca Raton: CRC, 2001
Hsieh M. Recommendations for treatment of hyponatraemia at endurance events. Sports Med. 2004; 34(4):231-8.

Murray R, Stofan J, Eichner ER. Hyponatremia in athletes. Sports Science Exchange. 2003:16, 1-6. Leiper JB. Gastric emptying and intestinal absorption of fluids, carbohydrates, and electrolytes. In: Sports Drinks: Basic and Practical Aspects, 2001;89-128.

Sharp RL. Role of whole foods in promoting hydration after exercise in humans. J Am Coll Nutr. 2007; 26(5):5925-5965.

Meyer F. Bar-Or O. (1994). Fluid and electrolyte loss during exercise: The pediatric angle." "leading article". Sports Medicine. 1994; 18:4-9.

Wilk B, Bar-Or O. Effect of drink flavor and $\mathrm{NaCl}$ on voluntary drinking and hydration in boys exercising in the heat. J Appl Physiol. 1996; 80:1112-1117.

Wilk B, Kriemler S, Keller H, Bar-Or O. Consistency in preventing voluntary dehydration in boys who drink a flavored carbohydrate-NaCl beverage during exercise in the heat. Intern J Sport Nutr. 1998; 8:1-9. Rivera-Brown AM, Gutiérrez R, Gutiérrez JC, Frontera WR, Bar-Or O. Drink composition, voluntary drinking, and fluid balance in exercising, trained, heat-acclimatized boys. J Appl Physiol. 1999:86:78-84.

Horswill CA, Passe DH, Stofan JR, Horn MK, Murray, R. Adequacy of fluid ingestion in adolescents and adults during moderate-intensity exercise. Pediatric Exercise Sci. 2005; 17:41-50.

Wilk B, Rivera-Brown AM, Bar-Or O. Voluntary drinking and hydration in non-acclimatized girls exercising in the heat. Eur J Appl Physiol. 2007, 101(6):727-34.

Rivera-Brown AM, Ramírez-Marrero FA, Wilk B, Bar-Or O. Voluntary drinking and hydration in trained heat-acclimatized girls exercising in a hot and humid climate. Eur J Appl Physiol. 2008; 103(1):109-16. Dufour A., Candas V. Ageing and thermal responses during passive heat exposure: sweating and sensory aspects. Eur J Appl Physiol. 2007; 100:19-26.

Kenney WL, Chiu P. Influence of age on thirst and fluid intake. Med Sci Sports Exerc. 2001; 33 (9):1524-1532. Shirreffs SM, Armstrong LE, Cheuvront SN. Fluid and electrolyte needs for preparation and recovery from training and competition. J Sports Sci. 2004; 22:57-63.

Coyle EF. Fluid and fuel intake during exercise. J Sports Sci. 2004; 22(1): 39-55.

Marino FE, Kay D, Cannon J. Glycerol hyperhydration fails to improve endurance performance and thermoregulation in humans in a warm humid environment. Pflugers Arch. 2003; 446 (4): $455-62$

Latzka WA, Sawka MN. Hyperhydration and glycerol: thermoregulatory effects during exercise in hot climates. Can J Appl Physiol. 2000; 25(6):536-45

American Academy of Pediatrics. Climatic Heat Stress and the Exercise Child and Adolescent. Pediatrics. 2000;106:158-9.

\section{Suplementos alimentares}

Bill Campbell B, Kreider RB, Ziegenfuss T, Bounty PB, Roberts M, Burke D, et al. International Society of Sports Nutrition Position Stand: Protein and Exercise. J Int Soc of Sports Nutr. 2007; 4:8.

Lowery L, Forsythe CE. Protein and Overtraining: Potential Applications for Free-Living Athletes.J Inter Soc of Sports Nutr. 2006;3(1): 42-50.

Volek JS, Forsythe CE and Kraemer V.Nutritional aspects of women strength athletes-Br. J. Sports Med. 2006;40;742-748.

Cockburn E, Hayes PR, French DN, Stevenson E and Gibson ASC. Acute milk-based protein-CHO supplementation attenuates exercise-induced muscle damage; Appl. Physiol. Nutr. Metab.2008; 33: 775-783 Gaine PC, Pikosky MA, Bolster DR, Martin WF,Maresh ,CM and Rodrigues NR. Postexercise Whole-Body Protein Turnover Response to Three Levels of Protein Intake. Med Sci Sports Exerc. 2007; 39(3):480-6. Howatson G, Someren KAV. The Prevention and Treatment of Exercise- Induced Muscle Damage. Sports Med. 2008; 38 (6): 483-503.

Tang JE, Manolakos JJ, Kujbida GW, Lysecki PJ, Moore DR and Phillips SM. Minimal whey protein with carbohydrate stimlates muscle protein synthesis following resistance exercise in trained young men; Appl. Physiol. Nutr. Metab. 2007;32: 1132-1138

Kreider RB: Effects of creatine supplementation on performance and training adaptations. Mol Cell Biochem 2003, 244:89-94

Hultman E, Bergstrom J, Spreit L, Soderlund K: Energy metabolism and fatigue. In Biochemistry of Exercise VII Edited by: Taylor A, Gollnick PD, Green H. Human Kinetics: Champaign, IL; 1990:73-92.].

Uchida MC, Bacurau AVN, Aoki MS, Bacurau RFP. Consumo de Aminoácidos de Cadeia Ramificada não Afeta o Desempenho de Endurance. Rev Bras Med Esporte - Vol. 14, No 1 - Jan/Fev, 2008; Blomstrand E, Hassmén P, Ekblom B, Newsholme EA. Influence of ingesting a solution of branchedchainamino acids on perceived exertion during exercise. Acta Physiol Scand 1997; 159: 41-9

Joyner MJ, Glutamine and Arginine: Immunonutrients and Metabolic Modulators? Exercise and Sport Sciences Reviews

Kristensen, Julio Boza and Bente Klarlund Pedersen Karen Krzywkowski, Emil Wolsk Petersen, Kenneth Ostrowski, Jens Halkjær. Effect of glutamine supplementation on exercise-induced changes in lymphocyte function. Am J Physiol Cell Physiol 281:1259-1265, 2001)

\section{Drogas Lícitas e llícitas}

Informaçōes Sobre o Uso de Medicamentos no Esporte, 7a edição, RJ-Brasil, 2008 (www.cob.org.br). N. A. Mark Estes III et al. Task Force 9: Drugs and Performance-Enhancing Substances, in BETHESDA CONFERENCE REPORT. JACC 2005; 45 (8): 1368-9.

World Anti-Doping Agency (WADA). Athlete's Guide to the Doping Control Program. Available at: http:// www.wada-ama.org. 